\title{
Feo-hifomicose sistêmica em cão
}

\author{
Systemic phaeohyphomycosis in a dog
}

\begin{abstract}
Iana Carolina Pordeus Uchôa ${ }^{I^{*}}$ José Rômulo Soares Santos $^{\mathrm{I}}$ Almir Pereira de Souza ${ }^{\mathrm{II}}$ Antônio Flávio Medeiros Dantas"II Olívia Maria Moreira Borges ${ }^{\text {II }}$ Larissa Coutinho de Medeiros ${ }^{\text {III }}$
\end{abstract}

\section{- NOTA -}

\section{RESUMO}

Descrevem-se os achados clínicos, laboratoriais e histopatológicos de feo-hifomicose sistêmica em um cão. Clinicamente observou-se cansaço, ascite, apatia, hiporexia, perda de peso e polidipsia. $O$ animal estava sendo tratado para erliquiose e babesiose. Após 11 dias, o cão retornou com hepatopatia grave e veio a óbito em 48 horas. Na necropsia, observaram-se nódulos enegrecidos em vários órgãos da cavidade abdominal. Histologicamente, havia reação granulomatosa necrosante com hemorragia, associada a miríades de hifas fúngicas pigmentadas intralesionais em múltiplos órgãos, caracterizando feo-hifomicose sistêmica. Ressalta-se a importância de incluir esta doença no diagnóstico diferencial de hepatopatias graves em cães com ascite.

Palavras-chave: micoses sistêmicas, fungos dematiáceos, cão, hepatopatia, patologia.

\section{ABSTRACT}

The objective of this study was to describe clinical, laboratorial and histopathological findings of systemic phaeohyphomycosis in a dog. The animal was presented with a history of fatigue, ascites, lethargy, weight and appetite loss and polydipsia. The therapy for erliquiose and babesiosis was started. After 11 days, the dog returned with severe liver disease and died after forty-eight hours. At necropsy, there were black nodules in various abdominal organs. Histologically, necrotizing granulomatous reaction with hemorrhage associated with myriads of intralesional pigmented fungal hyphae was observed in multiple organs, characterizing systemic phaeohyphomycosis. Thus, it is important to include this illness in the differential diagnosis of severe liver diseases in dogs with ascites.

Key words: fungal infection, dematiaceous fungi, dog, hepatopathy, pathology.

Feo-hifomicose é um termo utilizado para descrever micoses oportunistas em humanos e animais (POUTAHIDIS et al., 2009), causadas por fungos dematiáceos, filamentosos, que possuem melanina na estrutura da parede celular e são comuns em climas quentes e úmidos. Apesar de ter distribuição cosmopolita, do conhecimento dos autores, no Brasil, há apenas um caso descrito em cão, com envolvimento cutâneo (BASSO et al., 2008). A etiologia é composta por uma grande variedade de fungos, que se desenvolvem nos tecidos do hospedeiro na forma de hifas septadas, pseudo-hifas ou leveduras negras (FERREIRO et al., 2007), dentre as quais foram identificadas Scopulariopsis chartarum (WELSH \& ELY, 1999), Cladophialophora bantiana (ANÕR et al., 2001), Ochroconis gallopavum (SINGH et al., 2006), Exophiala sp (BASSO et al., 2008), Cladosporium

IPrograma de Pós-graduação em Medicina Veterinária, Centro de Saúde e Tecnologia Rural (CSTR), Universidade Federal de Campina Grande (UFCG), Av. Santa Cecília, s/n, 58708-110, Patos, PB, Brasil. E-mail: ianapordeus@hotmail.com.*Autor para correspondência.

IIUnidade Acadêmica de Medicina Veterinária, CSTR, UFCG, Patos, PB, Brasil.

IIPrograma de Aperfeiçoamento em Medicina Veterinária, CSTR, UFCG, Patos, PB, Brasil. 
cladosporioides (POUTAHIDIS et al., 2009) entre outras, todos em cães com feo-hifomicose.

O diagnóstico é realizado pela observação das hifas marrom-amareladas no exame histopatológico, sendo necessária cultura para identificação da espécie ou realização da Reação de Polimerase em Cadeia (PCR) e imuno-histoquímica(IHQ) (POUTAHIDIS et al., 2009). Devido ao diagnóstico tardio e à falta de um tratamento eficaz, a morte costuma ocorrer em menos de um ano (CALIGIORNE et al., 2010). Descrevem-se os achados clínicos, laboratoriais e histopatológicos de feo-hifomicose sistêmica em um cão.

Um cão macho, da raça Cocker Spaniel, com oito anos de idade, foi atendido no Hospital Veterinário da Universidade Federal de Campina Grande (HVUFCG), Campus de Patos - PB, apresentando cansaço, distensão abdominal, apatia, hiporexia, perda de peso e polidipsia. O proprietário relatou que o animal havia tido carrapatos e problemas de pele recorrentes, com feridas e perda de pelos. Ao exame físico, observaramse mucosas conjuntival e oral discretamente ictéricas, linfonodos poplíteos e submandibulares hipertrofiados, distensão abdominal intensa com piparote positivo. Foram encontradas alterações como trombocitopenia, anemia normocítica normocrômica, leucopenia com linfopenia e transudato modificado no líquido ascítico. Instituiu-se o tratamento convencional para erliquiose e babesiose, protetor hepático e suplementos vitamínico e mineral.

Após 11 dias, o cão apresentou perda de peso, apatia, desidratação moderada, icterícia generalizada, dificuldade de locomoção, dispneia, distensão abdominal acentuada, sensibilidade dolorosa à palpação do abdome, petéquias na pele da região abdomial, poliúria, polidipsia e fezes pastosas enegrecidas externamente com coloração alaranjada em seu interior. O quadro hematológico estava semelhante, com exceção das plaquetas e leucócitos que normalizaram e o plasma que estava ictérico. $\mathrm{Na}$ bioquímica sérica, observou-se aumento das bilirrubinas total $\left(8,70 \mathrm{mg} \mathrm{dL}^{-1}\right)$, direta $\left(7,26 \mathrm{mg} \mathrm{dL}^{-1}\right)$ e indireta $\left(1,44 \mathrm{mg} \mathrm{dL}^{-1}\right)$, das enzimas hepáticas ALT (298U $\left.\mathrm{mL}^{-1}\right)$ eAST (340 $\left.\mathrm{mL}^{-1}\right)$ e dos níveis de ureia $\left(60 \mathrm{mg} \mathrm{dL}^{-1}\right)$.

Na ultrassonografia abdominal, verificou-se ascite e formações císticas anecogênicas múltiplas no fígado com hepatomegalia, enquanto no baço verificouse uma massa hiperecoica a isoecoica e esplenomegalia. O fluído abdominal estava vermelho-amarelado e, na urinálise, detectaram-se leucócitos e cristais de bilirrubina em grande quantidade. $\mathrm{O}$ animal ficou internado durante dois dias e apresentou episódios de êmese verde-alaranjada, evoluindo rapidamente para prostração, vocalização, letargia e morte.
$\mathrm{Na}$ necropsia, observou-se icterícia generalizada moderada, distensão abdominal contendo líquido avermelhado com grumos amarelados e petéquias e equimoses na pele da região abdominal ventral. As lesões macroscópicas observadas foram mais acentuadas no fígado e baço. Havia hepatomegalia e esplenomegalia. Na superfície capsular desses órgãos, observaram-se áreas enegrecidas arredondadas, múltiplas a coalescentes, variando de 0,3 a $1,5 \mathrm{~cm}$ de diâmetro, algumas centralmente esverdeadas com bordos enegrecidos (Figura 1A), distribuídas por toda superfície capsular. Ao corte, elas se aprofundavam ao parênquima, muitas vezes, formando cavitações císticas, contendo material amarelado e pastoso, limitadas por cápsula de tecido esbranquiçado. $\mathrm{O}$ fígado estava discretamente amarelado com acentuação do padrão lobular. No linfonodo hepático, observou-se uma área focal enegrecida na superfície cortical, e achados semelhantes nos rins, cérebro (Figura 1B e 1C) e testículo direito.

As lesões histológicas no fígado (Figura 1D), baço (Figura 1E), cérebro, rins, linfonodo hepático e testículo, coradas pela Hematoxilina e Eosina (HE), foram semelhantes e características de reação inflamatória granulomatosa e necrosante. Observaramse focos de necrose circundados por infiltrado de macrófagos, células epitelioides e células gigantes multinucleadas, além de linfócitos, plasmócitos e raros neutrófilos, limitados por discreta proliferação de tecido conjuntivo fibroso, formando granulomas. Grande número de estruturas tubuliformes septadas e marromamareladas, características de hifas pigmentadas, estavam presentes em todas as áreas necróticas, por vezes sendo fagocitadas por células gigantes, as quais foram observadas no interior de vasos, associadas a trombos de fibrina. As hifas também foram coradas pelo ácido periódico de Schiff (PAS) e Gomori. Fragmentos de lesões, processados e cortados rotineiramente para histopatologia e observados em lâminas apenas desparafinizadas e montadas (não coradas pela $\mathrm{HE}$ ), revelaram hifas fúngicas amarronzadas (Figura 1F), confirmando tratar-se de fungo pigmentado com características morfológicas compatíveis com feohifomicetos.

Durante as duas últimas décadas, as feohifomicoses têm sido cada vez mais frequentes em animais (FERREIRO et al., 2007). A forma sistêmica é rara em carnívoros, mas existem casos em cães (SCHOROEDER et al., 1994; WELSH \& ELY, 1999; HERRÁEZ et al., 2001; SINGH et al., 2006) e em gatos (ABRAMO et al., 2002; ELIÈS et al., 2003). A origem da infecção sistêmica neste caso não está clara. Acreditase que as repetidas lesões cutâneas anteriores à micose 


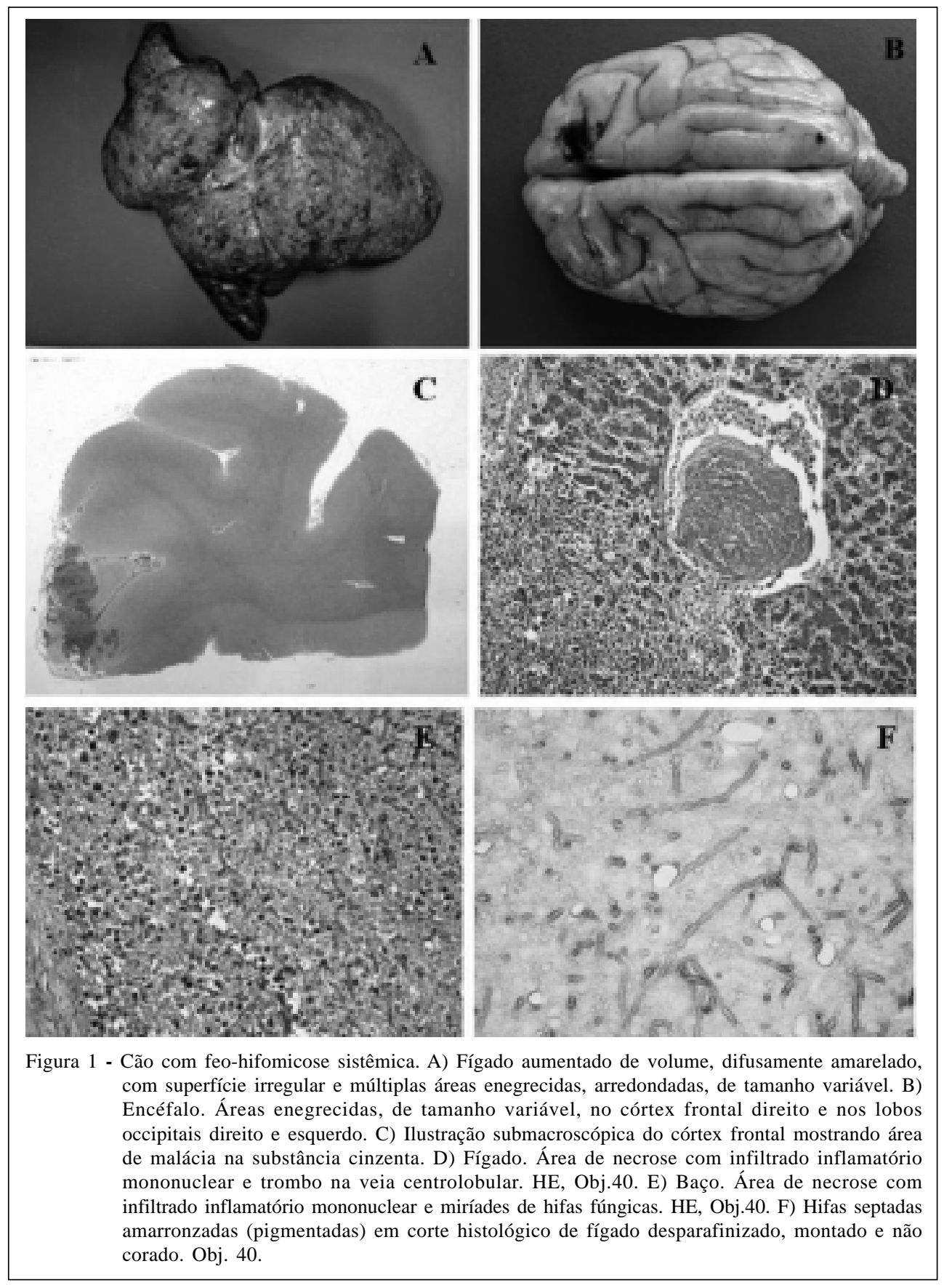

sistêmica tenham sido a principal porta de entrada, aliada ao estado de imunossupressão, já que os fungos dematiáceos são oportunistas. Este fato foi semelhante ao encontrado por ABRAMO et al. (2002) e por DAMICO et al. (2011), em gatos, e HERRÁEZ et al. (2001) em cão, ambos descrevem lesões cutâneas anteriores à infecção micótica. Outra possível via de contaminação seria a nasal ou rhino-sinusal, através da inalação do agente.
Mesmo com a conduta terapêutica para erliquiose e babesiose, protetores hepáticos e aminoácidos essenciais, o cão retornou apresentando um quadro de hepatopatia grave, justificando-se, posteriormente, pelas lesões hepáticas císticas, e histopatológicas, com áreas de necrose associadas às hifas fúngicas. Alguns relatos descrevem alterações semelhantes ao deste estudo em cães com feohifomicose sistêmica, um deles com hepatomegalia 
(ANÕR et al., 2001), outro com ascite e esplenomegalia (SINGH et al., 2006), achados estes também verificados em um gato (ELIÈS et al., 2003) acometido pela forma sistêmica.

Neste relato, observou-se elevação das bilirrubinas, e consequentemente icterícia, o que foi semelhante ao estudo de um cão com feo-hifomicose sistêmica (ANÕR et al., 2001). Além disso, o animal apresentou aumento da atividade sérica de enzimas hepáticas, fato também descrito em um gato com feohifomicose sistêmica, causada por Cladophialophora bantiana, que apresentava lesões no fígado (ELIÈS et al., 2003).

Não foi possível estabelecer o diagnóstico clínico pela biópsia hepática, pois o animal morreu subitamente. O diagnóstico definitivo foi estabelecido pela necropsia e presença de fungos dematiáceos no fígado, baço, rins, linfonodo hepático, testículo direito e cérebro, caracterizando feo-hifomicose sistêmica, também observado por ANÕR et al. (2001) e ELIÈS et al. (2003). Entretanto, não foi coletado material para exame micológico, tendo em vista a suspeita primária da enfermidade não ser uma infecção fúngica.

Apesar dos níveis séricos de ureia estarem aumentados e do envolvimento renal, as lesões não eram suficientes para causar insuficiência renal. Observaram-se também lesões no encéfalo, semelhantes às observadas por ANÕR et al. (2001) em um cão.

A observação de hifas pigmentadas intralesionais permite sugerir uma infecção por fungos dematiáceos (BEALE \& PINSON, 1990) e a natureza infecciosa e patogênica poderia ser demonstrada pela observação histopatológica da lesão e do agente nos tecidos (FERREIRO et al., 2007). Entretanto, por ser uma doença rara, é diagnosticada, na maioria dos casos, pela necropsia.

Vários gêneros de fungos com características histomorfológicas similares podem causar feo-hifomicose, sendo necessária a realização de imuno-histoquímica ou o cultivo para identificação do agente (BEALE \& PINSON, 1990). Neste relato, suspeita-se que seja $\boldsymbol{C}$. bantiana, por ser neurotrópico e o mais encontrado na forma cerebral e sistêmica (ELIÈS et al., 2003; POUTAHIDIS et al., 2009).

Diante dos achados clínicos, laboratoriais e patológicos descritos neste estudo, pode-se concluir que infecções fúngicas como a feo-hifomicose sistêmica devem ser incluídas no diagnóstico diferencial de patologias sistêmicas não responsivas a tratamento, que apresentem quadros de ascite e hepatopatia.
Yomuiri Online - Japão

La Información - Espanha

Spiegel Online-Alemanha

盆裁-Japão

Focus Online - Alemanha

Marmiton.org - França

Sueddeustsche.de - Alemanha

OneIndia-hindi

Los Angeles Times - Estados Unidos

Guardian.co.uk - Reino Unido

Vogue - França

Elle - França

\section{COMITÊ DE ÉTICA E BIOSSEGURANÇA}

Os autores se responsabilizam por toda descrição e metodologia adotadas em relação ao artigo.

\section{REFERÊNCIAS}

ABRAMO, F. et al. Feline cutaneous phaeohyphomycosis due to Cladophialophora bantiana. Journal of Feline Medicine Surgery, v.4, n.3, p.157-163, 2002. Disponível em: <http:// www.sciencedirect.com/science/article/pi i / S1098612X0290183X>. Acesso em: 01 ago. 2011. doi: 10.1053/jfms.2002.0183.

ANÕR, S. et al. Systemic Phaeohyphomycosis (Cladophialophora bantiana) in a dog-clinical diagnosis with stereotactic computed tomographic-Guided Brain Biopsy. Journal of Veterinary Internal Medicine, v.15, p.257261, 2001. Disponível em: <http://onlinelibrary.wiley.com/ doi/10.1111/j.1939-1676.2001.tb02321.x/abstract>. Acesso em: 01 ago. 2011.

BASSO, P.C. et al. Dermatomicose e ceratite micótica causada por Exophiala sp. em um cão. Ciência Rural, v.38, n.7, p.2063-2067, 2008. Disponível em: <http://www.scielo.br/ scielo.php? script = sci_art text \& pid = S 0103 84782008000700044>. Acesso em: 04 ago. 2011. doi: org/ $10.1590 / \mathrm{S} 0103-84782008000700044$.

BEALE, K.M.; PINSON, D. Phaeohyphomycosis caused by two different species of Curvularia in two animals from the same household. Journal of the American Animal Hospital Association, v.26, n.1, p.67-70, 1990. Disponível em: <http:/ /www.cabdirect.org/abstracts/19902212403.html>. Acesso em: 05 ago. 2011.

CALIGIORNE, R.B. et al. Fungos dematiáceos. Biotecnologia Ciência \& Desenvolvimento. n.1, p.22-25, 2010. Disponível em: <http://www.biotecnologia.com.br/revista/bio11/ fungos.pdf $>$. Acesso em: 05 ago. 2011.

DAMICO, C.B. et al. Feohifomicose cutânea em gatos - relato de dois casos. Clínica Veterinária. n.93, p.64-70, 2011.

ELIÈS, L. et al. Fatal systemic Phaeohyphomycosis in a cat due to Cladophialophora bantiana. Journal of Veterinary Medicine, v.50, p.50-53, 2003. Disponível em: <http:// www.ncbi.nlm.nih.gov/pubmed/12650510>. Acesso em: 05 ago. 2011. 
FERREIRO, L. et al. Feo-hifomicoses: infecções micóticas emergentes. Acta Scientiae Veterinariae, v.35, n.2, p.239241, 2007. Disponível em: <http://www.ufrgs.br/actavet/35suple-2/07\%20-\%20ANCLIVEPA.pdf>. Acesso em: 08 ago. 2011.

HERRÁEZ, P. et al. Invasive Phaeohyphomycosis caused by Curvularia species in a dog. Veterinary Pathology, v.38, p.456459, 2001. Disponível em: <http://www.ncbi.nlm.nih.gov/ pubmed/11467482>. Acesso em: 05 ago. 2011.

POUTAHIDIS, T. et al. Mycotic encephatitis and nephritis in a dog due to infection with Cladosporium cladosporioides. Journal of Comparative Pathology, v.140, p.59-63, 2009. Disponível em: <http://www.sciencedirect.com/science/article/ pii/S0021997508001102>. Acesso em: 08 ago. 2011. doi: 10.1016/j.jсра.2008.09.002.
SINGH, K. et al. Fatal systemic phaeohyphomycosis caused by Ochroconis gallopavum in a dog. Veterinary Pathology, v.43, p.988-992, 2006. Disponível em: <http://www.ncbi.nlm.nih.gov/ pubmed/17099156>. Acesso em: 02 ago. 2011.

SCHOROEDER, H. et al. Systemic phaeohyphomycosis caused by Xylohypha bantiana in a dog. Journal of South African Veterinary Association, v.65, p.175-178, 1994. Disponível em: <http://www.ncbi.nlm.nih.gov/pubmed/7602573>. Acesso em: 01 ago. 2011.

WELSH, R.D.; ELY, R.W. Scopulariopsis chartarum systemic mycosis in a dog. Journal of Clinical Microbiology, v.37, p.2102-2103, 1999. Disponível em: <http:// www.ncbi.nlm.nih.gov/pmc/articles/PMC85049/>. Acesso em: 08 ago. 2011. 